Voerman, B., Fischer, M., Visser, A., Garssen, B., Andel, G. van, Bensing, J. Health-related quality of life in Dutch men with prostate cancer. Journal of Psychosocial Oncology: 2006, 24(2), 49-64

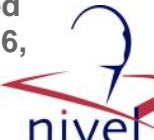

\begin{tabular}{|l|l|}
$\begin{array}{l}\text { Postprint } \\
\text { Version }\end{array}$ & 1.0 \\
\hline Journal website & \\
\hline Pubmed link & http://www.ncbi.nlm.nih.gov/pubmed/17046806 \\
\hline DOI &
\end{tabular}

This is a NIVEL certified Post Print, more info at http://www.nivel.eu

\title{
Health-Related Quality of Life in Dutch Men with Prostate Cancer
}

\author{
Bert Voerman, MA MaArten Fischer, MA AdriaAn Visser, PhD Bert Garssen, PhD \\ GEORGE VAN ANDEL, MD, PHD JOZIEN BENSING, PHD
}

\begin{abstract}
.
Prostate cancer is the most prevalent solid malignancy in men in the Netherlands. With regard to treatment, the focus of attention has shifted in the last decade from pure survival rates to health-related quality of life. HRQOL is affected differently by different treatments. The objective of this study is to assess the HRQOL related to treatment regime and time since diagnosis in Dutch men with prostate cancer. We conducted a cross-sectional study among 238 men with prostate cancer in a heterogeneous sample who filled in a general health-related quality-of-life measure (EORTC-QLQ-C30) and a prostate cancer specific quality-of-life instrument (the EORTC-QLQ-PR25) and a Joy-of-Life questionnaire. Men on hormonal treatment are doing worse compared with other treatments with respect to physical functioning, role functioning, fatigue, pain and sexual functioning. No differences were found between radical prostatectomy and radiation therapy on any of the HRQOL dimensions nor for time since diagnosis. In hormonal therapy, men who are diagnosed longer than two years ago report a worse cognitive functioning and more burdens from urinary problems.
\end{abstract}

\section{INTRODUCTION}

Prostate cancer is currently one of the most frequent diagnosed cancers in the western world with 38.7 million men in North America, Europe and Japan affected by this disease (Black et al., 1997; Landis et al., 1998). In the Netherlands each year 7000 new cases are diagnosed (Visser et al., 2002; Landis et al., 1998). Prostate cancer mostly affects older men. Under the age of 50 there is hardly any risk, but with increasing age the chances of developing prostate cancer also increases, making age an important risk factor (Gulden et al., 1994). Treatment options depend on the stage of the disease. For local disease, radical prostatectomy (surgical removal of the entire prostate gland) or radiation therapy (external or interstitial) are most widely 
Voerman, B., Fischer, M., Visser, A., Garssen, B., Andel, G. van, Bensing, J. Health-related quality of life in Dutch men with prostate cancer. Journal of Psychosocial Oncology: 2006, 24(2), 49-64

used as a curative treatment. In case of locally advanced disease or distant metastasis, there is no curative treatment available at this moment. Hormonal therapy is, then, mostly used to slow down the growth of prostate tissue, including the malignant type. Depending on the medical condition, combinations of treatment options are possibly given. For any stage of the disease, watchful waiting can be a reasonable "treatment" option (Aus et al., 2001). The treatment modalities often cause serious side effects. Radical prostatectomy can cause urinary incontinence (0\%-50\%), micturation problems (0.5\%-15\%) and erectile dysfunction 29\%-100\%) (Davinson et al., 1996; Hautmann et al., 1994). Radiation therapy may lead to erectile dysfunction (55\%$67 \%)$, rectal bleeding (3\%-11\%), diarrhoea (1\%-8\%) and passing bloody stools (3\%$11 \%$ ) (Shipley et al., 1994). Hormonal treatment almost always leads to loss of libido and may cause hot flushes, breast forming and fatigue (Catalona, 1994). Watchful waiting can cause anxiety by having cancer without receiving any treatment (Hedestig et al., 2003). In terms of survival rate, there is no consensus on what treatment is best (Wasson et al., 1993) and new treatment modalities seldom lead to revolutionary improvements in treatments and life expectancy. These facts have evoked a shift of attention to not only focus on the quantity of life but also to the health-related quality of life (HRQOL). There is a wide consensus among researchers that HRQOL is a multi-dimensional concept. These dimensions or domains include at least the following four domains. The first domain is the physical health, meaning bodily functions like continence or absence of pain. The second is the functional health, expressing functions like self-care, mobility and role activities. Third is social health, indicating the quality of interpersonal relationships; and fourth, the psychological health, indicating cognitive function, psychiatric morbidity and psychological distress (Litwin et al., 1999a; Macdonagh, 1996). HRQOL has become an important outcome measure for clinical trials, especially when the expected differences in survival rates are small (Aaronson et al., 1993; Feld, 1995; Moinpour, 1994). HRQOL provides an overview of the range of side effects and the impacts on life of the treatment. This makes it possible to assess rehabilitation needs, and it can be used as predictor of response to future treatment (Cella \& Tulsky, 1993). Other reasons for rating the HRQOL are to assess the long-term effects of treatments, and HRQOL considerations are potential relevant to the treatment decision process. Many studies describe the HRQOL for different treatment modalities or compare the HRQOL between treatments after a certain period of time. For radical prostatecomy, it was found that 12 months after the treatment, 7\%-39\% incontinence disorder occurs and 14\%-69\% erectile disorder (Walsh et al., 1994; Litwin et al., 1999b). Except from sexual and urinary function, 12 months after radical prostatectomy $86 \%-97 \%$ of the patients returned to baseline level of all the domains of HRQOL (Litwin et al., 1999b). Urinary incontinence and sexual dysfunction was found in a substantial proportion of men who underwent radical prostatectomy one to nine years ago (median 41 months). Except from these problems, the overall HRQOL in these patients were similar among age-matched controls. Radiation therapy leads mainly to impairment of sexual function, whereas bowel function problems have decreased in 24 months (Hamilton et al., 2001). The effect on other domains of HRQOL is very small one year after treatment (Beard et al., 1997). On the longer term, the same results are obtained by Caffo et al. (1996). They found increased frequency of urinating and incontinence as well as serious impairment of sexual function in patients who were treated longer ago (median 35 months) (Lilleby et al., 1999). 
Voerman, B., Fischer, M., Visser, A., Garssen, B., Andel, G. van, Bensing, J. Health-related quality of life in Dutch men with prostate cancer. Journal of Psychosocial Oncology: 2006, 24(2), 49-64

Comparing radical prostatectomy with radiation therapy, studies are indicating that incontinence and erectile dysfunction are more prevalent in radical prostatectomy, whereas bladder irritation and bowel problems are more present in radiation therapy (Talcott et al., 1998). One study found no differences in HRQOL between radical prostatectomy and radiation therapy one year after treatment (Lee et al., 2001). A study that compared radiation therapy and radical prostatectomy long after treatment shows a similar pattern. After a median of 31 and 41 months after radiation therapy and radical prostatectomy respectively, a substantial portion of the irradiated patients report sexual dysfunction and bowel problems, whereas the operated patients report urinary problems and sexual dysfunction. In other domains of HRQOL, there is no difference between radiation therapy and radical prostatectomy (Lilleby et al., 1999). Research in men receiving hormone therapy is showing negative effects on various aspects of the HRQOL. Andel and Kurth (2003), compared men who received single or combined androgen suppression immediately with men with delayed treatment, which showed that immediate treatment has a negative effect on energy, fatigue, emotional, physical and sexual function, and also produced hot flushes. A study on men who have received hormonal therapy for an average of 45 months shows that on the longer run physical functioning, role functioning and sexual functioning are worse in men on hormonal therapy compared with patients not receiving hormonal treatment. The aim of the present study is to give a description of the HRQOL in Dutch men with prostate cancer. HRQOL is related to treatment regimes and to time since diagnosis.

\section{METHODS}

\section{Sampling}

This study is part of a larger project assessing the HRQOL, the psychosocial problems in men with prostate cancer and their need for psychosocial support. For recruitment of patients, folders with a response card were used, providing information about the study. These folders were handed out by urologists in five hospitals, at local educational meetings about prostate cancer and by direct mailing to all members of the patients' association. There was also an announcement on a website on cancer (www.kanker-actueel.nl) and an advertisement was placed in a local newspaper. The folders also reached patients by means of other control (e.g., by friends, family). The patients could indicate whether they wanted to participate in the study by only filling in questionnaires or by joining a support group of seven sessions, combined with filling out questionnaires.

\section{Instruments}

The questionnaire included questions on the demographics, socioeconomic status, medical status, treatment, HRQOL and psychosocial characteristics. HRQOL is measured by the European Organisation for Research and Treatment of Cancer core module EORTC-QLQ-C30, version 3.0 (Aaronson et al., 1993), and the The EORTC PR 25 prostate cancer module (Aaronson, 2002). The QLQ core module consists of 30 items of the Likert type, concerning physical, emotional, cognitive and role functioning in multi-item scales, as well as nine items measuring symptoms such as pain, fatigue, nausea and dyspnoe. In addition, there are two items on general health and general QOL, forming a general HRQOL scale. The EORTC PR 25 prostate cancer module (Aaronson, 2002) measures symptoms and problems specific for 
Voerman, B., Fischer, M., Visser, A., Garssen, B., Andel, G. van, Bensing, J. Health-related quality of life in Dutch men with prostate cancer. Journal of Psychosocial Oncology: 2006, 24(2), 49-64

prostate cancer patients. This questionnaire is still in development; it is constructed to form subscales on urinary symptoms, bowel symptoms, hormone treatment related problems and sexual function. HRQOL is mainly expressed in terms of symptoms and or problems in the EORTC questionnaires. Therefore, as an additional positive measure of quality of life we included the Joy in Life subscale of the Health and Disease Inventory (Bruin \& Dijk, 1996). The original questionnaire consists of 41 items, forming a Joy in Life scale (13 items) and a malaise subscale (28 items). Since we are only interested in the joy-of-life scale, we only included four negative items in place as "filler" items.

\section{RESULTS}

Urologists handed out 224 folders in five hospitals, 121 folders were distributed at local educational meetings and all members of the SCP (418) received the folder by mail. Also 21 folders found their way to men in other ways. Thus in total 784 patients were approached. As a result, 78 patients from hospitals, 20 patients from educational meetings, 157 from the SCP and 5 patients from a variety of other sources enrolled in the study, giving a total of 260 patients who returned the first questionnaire. Inclusion criteria are-having prostate cancer, having no other form of cancer or another disease that might affect the HRQOL and sufficiently master the Dutch language. After having excluded the patients that did not meet these criteria or did have too many missing values, 238 patients out of which 48 patients participated in our support groups, form our sample. Background characteristics are presented in Table 1.

\section{Background Characteristics}

The mean age is 67.9 years; by far most men are married, and most men have an education of at least high school level. The majority of the participants have been diagnosed more than two years ago, the mean time since diagnosis is 44.3 (SD 31.3) months with a range of 1-139 months. More than two-third of them had local disease. Treatments are mostly surgery or radiation therapy.

\section{Reliability of the Questionnaires}

Cronbach's alpha reliability coefficients of the EORTC QOL-C30 vary from 0.62 for the nausea subscale to 0.87 for the general healthrelated quality of life. Based on theoretical considerations, the urinary symptoms scale of the EORTC PR 25 module is split into a "level of urinary problems" and a "burden urinary problems" subscale, with Cronbach's alphas of 0.70 and 0.71 , respectively. A poor Cronbach's alpha was found for the bowel problems subscale (0.49) and the problems related to hormonal treatment subscale (0.37). However, the EORTC PR 25 scales constitute rather an inventory of symptoms than the measurement of a theoretical construct. Therefore a low alpha does not necessarily mean that the measurement of symptoms is inadequate. The sexual function scale has a Cronbach's alpha of 0.69. Finally, the reliability coefficient for the Joy in Life subscale is 0.87 .

\section{Comparison with External Group}

The general mean scores on all the aspects of HRQOL are showed in Table 2. A comparison was made between the scores obtained in the present study and a large international sample from the EORTC (Fayers et al., 1999). As Table 2 indicates, for almost every dimension, the men in our sample have a better functioning and suffer less from symptoms than in the EORTC sample. The data on the EORTC PR 25 are 
Voerman, B., Fischer, M., Visser, A., Garssen, B., Andel, G. van, Bensing, J. Health-related quality of life in Dutch men with prostate cancer. Journal of Psychosocial Oncology: 2006, 24(2), 49-64

not yet available from the EORTC data set and the Joy-of-Life scale is specific for the present project.

\section{[TABLE 1]}

\section{Comparing Different Treatments}

In Table 3 the mean scores on different aspects of the HRQOL are compared with the different treatments by means of Anovas. Higher scores in function scales indicate better functioning, higher scores on symptom scales indicate that symptom to be more severe.

\section{[TABLE 2]}

To compensate for multiple testing, the Bonferroni procedure is carried out, requiring an alpha of $p=0.002$ to reach significance. To investigate the differences between the specific treatment groups, GamesHowel post hoc test for unequal groups variances were performed. For different treatment modalities, significant differences are found for physical functioning, role functioning, general HRQOL, problems related to hormonal treatment and sexual functioning. Concerning the function scales, Table 3 indicates that there are differences in physical and role functioning between different treatments. Men, who underwent a combination of radical prostatectomy and radiotherapy, or radical prostatectomy as mono treatment, have a better physical function than men who are on hormonal treatment. Also, men who received a combination of radical prostatectomy and radiation therapy have a better physical functioning compared with only radiation treatment. All subjects who received the combination of radical prostatectomy and radiotherapy scored role functioning at the maximum. This differs significantly from men having received radiotherapy and men receiving hormone therapy. No differences have been found for emotional functioning, cognitive functioning and social functioning with respect to different treatments. The symptom scales indicate that fatigue is most prevalent in men receiving hormone therapy, more than in radical prostatectomy combined with radiotherapy and watchful waiting. Pain is more severe in men who received hormonal treatment compared with men treated having radical prostatectomy combined with radiotherapy and watchful waiting. However, these differences on fatigue and pain between groups disappear after the Bonferroni correction. The lowest general quality of life is reported by men on hormonal therapy, compared with RP and RT and watchful waiting. With respect to the prostate cancer specific symptoms, problems related to hormonal treatment and sexual functioning are the areas with differences between treatment modalities. Both problems related to hormonal treatment and a lower sexual function are scored higher by men on hormonal treatment than in any other treatment. Since age can be an important factor with respect to what treatment option is suitable for a patient, it was checked whether the age was different among the treatment groups. The mean ages are indeed significantly different between hormonal therapy (69.4 yrs, SD 8.5) and radical prostatectomy (64.3 yrs, SD 6.5). The Anova's were carried out again, with age as covariate. After controlling for age, physical functioning is still significantly different among the groups $(\mathrm{p}<0.001)$ as described; only the difference between radiotherapy and the combination of radiotherapy and radical prostatectomy disappeared. The difference for role functioning disappeared after controlling for age 
Voerman, B., Fischer, M., Visser, A., Garssen, B., Andel, G. van, Bensing, J. Health-related quality of life in Dutch men with prostate cancer. Journal of Psychosocial Oncology: 2006, 24(2), 49-64

$(p=0.004)$ since the Bonferroni correction prescribes alpha level of 0.002. The general health-related quality of life, as well as sexual function and the level of problems related to hormonal treatment are still significantly different among the treatment groups after controlling for age $(\mathrm{p}<0.001)$.

\section{[TABLE 3]}

\section{Time Since Diagnosis}

Men are divided into two groups: One group has been treated until maximal one year ago (mean 7 months, SD 3.3 months). The other group has been treated more than one year ago (mean 50 months, SD 29 months). These two groups are compared by means of a Kruskal-Wallis test for two groups. The results show that there are no differences in the general means of any of the HRQOL domains, nor in joy in life. However, when distinguished for treatment, some differences could be found between men who have been treated less than two years or more than two years ago. For men who are treated by radical prostatectomy, no differences are found. Nor are differences found for men treated with radiotherapy alone. Men on hormonal treatment regimes for more than one year report a worse cognitive functioning (mean $=81.4, \mathrm{SD}=20.0$ ) compared with men who receive hormones less than a year $(95.5$ $\mathrm{SD}=9.8) \mathrm{p}<0.01$. Men on hormonal treatment also report a greater burden of urological problems with a mean of 3.4 (SD 6.6) within the first year and a mean of 12.3 (SD 16.0) after more than one year $(\mathrm{p}<0.05)$. In men receiving both radical prostatectomy and radiotherapy, no differences were found between one or longer than one year after treatment. These comparisons could not be done for watchful waiting, since there were no men having watchful waiting after one year in our sample.

\section{DISCUSSION AND CONCLUSION}

In this study, the HRQOL was measured by the EORTC and completed with joy in life as a positive measure. The results obtained in the present study indicate that no difference between radical prostatectomy and radiotherapy could be found on any of the HRQOL dimensions more than three years after treatment. This result is in concordance with other studies that state that after a year there is no more chance in HRQOL (Lilleby et al., 1999). Another study however, shows that two years after treatment men who received radical prostatectomy suffer more from incontinence and impotence and in contrast men who receive radiotherapy suffer more from bowel problems (Potosky et al., 2000). Patients receiving hormonal treatment report, after more than three years of onset of that treatment, the lowest HRQOL on several dimensions. Hormone therapy oftentimes carries on for a lifetime; therefore the side effects may be still present at the time of our study. Remarkably, men who received both radical prostatectomy and radiation therapy report the best functioning of all groups in most of the HRQOL dimensions, especially the functional scales and joy in life. It is unknown what accounts for this result. One would expect more urological problems, erectile dysfunction and bowel problems after two different invasive treatments. The group patients receiving watchful waiting is the oldest, but with respect to several HRQOL dimensions they function very well compared with the group of men on hormonal therapy. Especially, the sexual functioning in the watchful waiting groups is the highest of all treatment groups. Although age is a 
Voerman, B., Fischer, M., Visser, A., Garssen, B., Andel, G. van, Bensing, J. Health-related quality of life in Dutch men with prostate cancer. Journal of Psychosocial Oncology: 2006, 24(2), 49-64

factor that is considered by the urologist in the decision what treatment would be best, it is not a factor influencing the impact of treatment modality itself on HRQOL factors. Whether the diagnosis and treatment was received less or more than a year ago seems only to be a factor of interest in hormonal treatment. Men receiving this treatment for longer than a year have a worse cognitive functioning and more burdens of urinary problems than men receiving this treatment for less then a year. In all treatment groups, even the one on hormones, the HRQOL is very high, significantly higher than in a large international sample from the EORTC. This indicates that our sample is biased toward men that function better in general, but this still does not impair the possibilities to compare treatment regimes. The conclusions have to be put in the light of the specific characteristics of the study. Since Anova is the most appropriate statistical test for the questions under research, it has been carried out, however, with violations of the assumptions. The variables are not normally distributed variables and group sizes are unequal. Also, multiple testing enhances the chances of type I error. To overcome these problems, the differences between treatment regimes have been checked non-parametrically, giving the same results. The multiple testing problem was compensated for by very conservative testing (Games-Howel) with very low alphas. This approach, however, may be evoking type II error. The clinical relevance of this study is that it could aid the treatment decision. On the long-term, no difference between HRQOL between radical prostatectomy and radiation therapy could be found. Whenever there is a choice whether or not to take hormonal therapy, it is clear that hormonal therapy has on the short- and the long-term a negative effect on many aspects of the HRQOL. It would, however, be beneficial for clinical practice if future HRQOL research follow patients longer in a prospective design with a larger sample.

\section{REFERENCES}

Aaronson, N.K. 15011/30011: An international field study of the reliability and validity of the EORTC QLQ-C30 and a disease specific questionnaire module (The QLQ-PR25 for assessing the quality of life of patients with prostate cancer. 2002. European Organisation for Research and Treatment of Cancer.

Aaronson, N.K., Ahmedzai, S., Bergman, B., Bullinger, M., Cull, A.M., \& Duez, M.J. (1993). The European Organisation for Research and Treatment of Cancer QLQ C30: a quality-oflife instrument for use in international clinical trials in oncology. Journal of the National Cancer Institute., 85, 365-376.

Andel, G.v. \& Kurth, K.H. (2003). The impact of androgen deprivation therapy on health related quality of life in asymptomatic men with lymph node positive prostate cancer. Euopean Urology, 44, 209-214.

Aus, G., Abbou, C.C., Pacik, D., Schmid, H.P., Van Poppel, H., Wolff, J.M., \& Zattoni, F. (2001). European Association of Urology guidelines on prostate cancer. European Urology, 40, 97-101.

Beard, C.J., Propert, K.J., Rieker, P.P., Clark, J.A., Kaplan, I., Kantoff, P.W., \& Talcott, J.A. (1997). Complications after treatment with external-beam irradiation in early-stage prostate cancer patients: A prospective multi-institutional outcome study. Journal of Clinical Oncology, 15, 223-229.

Black, R.J., Bray, F., Ferlay, J., \& Parkin, D.M. (1997). Cancer incidence and mortality in the European Union: Cancer registry data and estimates of national incidence for 1990. European Journal of Cancer, 33, 1075-1107.

Bruin, E.J.de. \& Dijk, M.van. HDI - Health and Disease Inventories, een meetinstrument voor aanpassing aan kanker. Handleiding. 1996. Lisse, Swets en Zeitlinger.

Caffo, O., Fellin, G., Graffer, U., \& Luciani, L. (1996). Assessment of quality of life after radical radiotherapy for prostate cancer. British Journal of Urology, 78, 557-563. 
Voerman, B., Fischer, M., Visser, A., Garssen, B., Andel, G. van, Bensing, J. Health-related quality of life in Dutch men with prostate cancer. Journal of Psychosocial Oncology: 2006, 24(2), 49-64

Catalona, W.J. (1994). Management of cancer of the prostate. New England Journal of Medicine, 331, 996-1004.

Cella, D.F. \& Tulsky, D.S. (1993). Quality of life in cancer: Definition, purpose, and method of measurement. Cancer Invest, 11, 327-336.

Davinson, P.J., Ouden D.van den, \& Schroeder, F.H. (1996). Radical prostatectomy: Prospective assessment of mortality and morbidity. European Urolology, 29, 168-173.

Fayers, P.M., Aaronson, N.K., Bjordal, K., \& Groenvold, M. EORTC QLQ-C30 Scoring Manual (Second edition). 1999. Brussels, EORTC.

Feld, R. (1995). Endpoints in cancer clinical trials: Is there a need for measuring quality of life? Supportive Care in Cancer, 3, 23-27.

Gulden, J.W.v.d., Kiemeney, L.A., Verbeek, A.L., \& Straatman, H. (1994). Mortality trend from prostate cancer in the Netherlands (1950-1989). Prostate, 24, 33-38.

Hamilton, A.S., Stanford, J.L., Gilliland, F.D., Albertsen, P.C., Stephenson, R.A., Hoffman, R.M., Eley, J.W., Harlan, L.C., \& Potosky, A.L. (2001). Health outcomes after externalbeam radiation therapy for clinically localized prostate cancer: Results from the Prostate cancer outcome study. Journal of Clinical Oncology, 7, 178-185.

Hautmann, R.E., Sauter, T.W., \& Wenderoth, U.K. (1994). Radical retropubic prostatectomy: Morbidity and urinary continence in 418 concecutive cases. Urology, 43, 47-51.

Hedestig, O., Sandman, P., \& Witmark, A. (2003). Living with untreated localized prostate cancer. Cancer Nursing, 26, 55-60.

Landis, S.H., Murray, T., Bolden, S., \& Wingo, P.A. (1998). Cancer statistics, 1998. CA. Cancer J. Clin., 48, 6-29.

Lee, W.R., Hall, M.C., McQuellon, R.P., Case, L.D., \& McCullough, D.L. (2001). A prospective quality-of-life study in men with clinically localized prostate carcinoma treated with radical prostatectomy, external beam radiotherapy, or interstitial brachytherapy. International Journal of Radiation Oncology, Biology, Physics, 51, 614-623.

Lilleby, W., Fossa, S.D., Waehre, H.R., \& Olsen, D.R. (1999). Long-term morbidity and quality of life in patients with localized prostate cancer undergoing definitive radiotherapy or radical prostatectomy. Int. J. Radiat. Oncol. Biol. Phys., 43, 735-743.

Litwin, M.S., Fitzpatrick, J.M., Fossa, S.D., \& Newling, D.W. (1999a). Defining an international research agenda for quality of life in men with prostate cancer. Prostate, 41 , 58-67.

Litwin, M.S., Mc Guigan, K.A., Shpall, A.I., \& Dhanani, N. (1999b). Recovery of healthrelated quality of life in the year after radical prostatectomy: Early experience. Journal of Urology, 161, 515-519.

Macdonagh, R. (1996). Quality of life and its assessments in urology. British Journal of Urology, 78, 485-496.

Moinpour, C.M. (1994). Measuring quality of life: An emerging science. Seminars in Oncology, 21, 48-60.

Potosky, A.L., Legler, J., Albertsen, P.C., Stanford, J.L., Gilliland, F.D., Hamilton, A.S., Eley, J.W., Stephenson, R.A., \& Harlan, L.C. (2000). Health outcomes after prostatectomy or radiotherapy for prostate cancer: Results from the Prostate Cancer Outcomes Study. J. Natl. Cancer Inst., 92, 1582-1592.

Shipley, W.U., Zietman, A.L., Hanks, G.E., Coen, J.J., Caplan, R.J., Won, M., Zagars, G.K., \& Asbell, S.O. (1994). Treatment related sequelae following external beam radiation for prostate cancer: A review with an update in patients with stages T1 and T2 tumor. Journal of Urology, 152, 1799-1805.

Talcott, J.A., Rieker, P.P., Clark, J.A., Propert, K.J., Weeks, J.C., \& Beard, C.J. (1998). Patient-reported symptoms after primary therapy for early prostate cancer: Results of a prospective cohort study. Journal of Clinical Oncology, 16, 275-283.

Visser, O., Coebergh, J.W.W., Schouten, L.J., Dijck, J.A.A.M.v., \& Siesling, S. (2002). Incidence of Cancer in the Netherlands. Utrecht, Vereninging van integrale kankercentra.

Walsh, P.C., Partin, A.W., \& Epstein, J.I. (1994). Cancer control and quality of life following anatomical radical retropubic prostatectomy: Results at 10 years. Journal of Urology, 152, 1831-1836.

Wasson, J.H., Cushman, C.C., Bruskewitz, R.C., Littenberg, B., Mulley, A.G.J., \& Wennberg, J.E. (1993). A structured literature review of treatment for localized prostate cancer.

Archives of Family Medicine, 2, 487-493. 
Voerman, B., Fischer, M., Visser, A., Garssen, B., Andel, G. van, Bensing, J. Health-related quality of life in Dutch men with prostate cancer. Journal of Psychosocial Oncology: 2006, 24(2), 49-64

\section{TABLES}

TABLE 1. Background characteristics of the patients $(\mathrm{N}=238)$

\begin{tabular}{lll}
\hline Age & & \\
\hline Mean (SD) & 67.9 & $(8.2)$ \\
$\quad$ Range & $42-86$ & \\
Marital status & & \\
$\quad$ Single & $18 \%$ & $(\mathrm{n}=43)$ \\
$\quad$ Married & $82 \%$ & $(\mathrm{n}=195)$ \\
Education & & \\
$\quad$ Low & $27 \%$ & $(\mathrm{n}=65)$ \\
$\quad$ Medium & $35 \%$ & $(\mathrm{n}=83)$ \\
High & $38 \%$ & $(\mathrm{n}=90)$ \\
Time since diagnosis & & \\
0-1 year & $14 \%$ & $(\mathrm{n}=33)$ \\
1-2 years & $21 \%$ & $(\mathrm{n}=51)$ \\
$>2$ years & $64 \%$ & $(\mathrm{n}=154)$ \\
Stage of disease & & \\
$\quad$ Local & $70 \%$ & $(\mathrm{n}=167)$ \\
$\quad$ Metastasis & $30 \%$ & $(\mathrm{n}=71)$ \\
Treatment & & \\
$\quad$ Radical prostatectomy (RP) & $26 \%$ & $(\mathrm{n}=62)$ \\
$\quad$ Radiation therapy (RT) & $16 \%$ & $(\mathrm{n}=38)$ \\
Hormone therapy (HT) & $47 \%$ & $(\mathrm{n}=112)$ \\
RP \& RT & $6 \%$ & $(\mathrm{n}=15)$ \\
Watchful waiting & $5 \%$ & $(\mathrm{n}=11)$ \\
\hline
\end{tabular}


Voerman, B., Fischer, M., Visser, A., Garssen, B., Andel, G. van, Bensing, J. Health-related quality of life in Dutch men with prostate cancer. Journal of Psychosocial Oncology: 2006, 24(2), 49-64

TABLE 2. Means of current sample compared to means of a large EORTC sample

\begin{tabular}{|c|c|c|c|c|}
\hline & $\begin{array}{l}\text { Mean Total } \\
n=238\end{array}$ & $\begin{array}{c}\text { EORTC } \\
\text { Reference group } \\
n=1314\end{array}$ & $\mathrm{t}$ value & $p$ value \\
\hline $\begin{array}{l}\text { C30 Functional Scales } \\
\text { (range } 0-100 \text { ) }\end{array}$ & Mean (SD) & Mean (SD) & & \\
\hline Physical functioning & $82.7(17.7)$ & $73.6(27.4)$ & 4.97 & $p<0.01$ \\
\hline Role functioning & $83.4(24.3)$ & $72.7(31.2)$ & 5.28 & $\mathrm{p}<0.01$ \\
\hline Emotional functioning & $80.5(20.4)$ & $79.7(22.4)$ & 0.50 & ns \\
\hline Cognitive functioning & $84.4(19.2)$ & $79.6(20.1)$ & 3.72 & $p<0.01$ \\
\hline Social functioning & $86.7(20.3)$ & $79.6(33.5)$ & 3.28 & $p<0.01$ \\
\hline \multicolumn{5}{|l|}{$\begin{array}{l}\text { C30 Symptom Scales } \\
\text { (range 0-100) }\end{array}$} \\
\hline Fatique & $25.8(22.3)$ & $33.7(27.8)$ & -4.18 & $p<0.01$ \\
\hline Pain & $14.9(21.3)$ & $24.1(28.6)$ & -4.76 & $\mathrm{p}<0.01$ \\
\hline Nausea \& vomiting & $2.2(8.8)$ & $5.3(11.6)$ & -3.95 & $p<0.01$ \\
\hline Appetite loss & $3.9(14.8)$ & $9.9(18.0)$ & -4.88 & $p<0.01$ \\
\hline Dyspnoea & $11.3(20.7)$ & $25.4(28.6)$ & -0.26 & ns \\
\hline Insomnia & $22.3(27.8)$ & $23.7(29.8)$ & -1.70 & $\mathrm{~ns}$ \\
\hline Constipation & $7.7(18.1)$ & $16.2(27.5)$ & -4.62 & $p<0.01$ \\
\hline Diarrhoea & $5.7(16.2)$ & $7.2(18.1)$ & -2.87 & $p<0.01$ \\
\hline Financial problems & $4.4(14.8)$ & $6.0(17.1)$ & -1.36 & ns \\
\hline \multicolumn{5}{|l|}{$\begin{array}{l}\text { C30 Total Score } \\
\text { (range 0-100) }\end{array}$} \\
\hline General quality of life & $76.3(16.7)$ & $67.3(25.2)$ & 5.34 & $p<0.01$ \\
\hline \multicolumn{5}{|l|}{$\begin{array}{l}\text { PR } 25 \text { Prostate Specific } \\
\text { Problems (range 0-100) }\end{array}$} \\
\hline Urological problems & $22.9(16.9)$ & - & & \\
\hline $\begin{array}{l}\text { Burden urological } \\
\text { problems }\end{array}$ & $10.3(16.0)$ & - & & \\
\hline Bowel problems & $5.5(9.5)$ & - & & \\
\hline $\begin{array}{l}\text { Problems hormonal } \\
\text { treatment }\end{array}$ & $12.9(11.9)$ & - & & \\
\hline Sexual problems & $79.5(21.4)$ & - & & \\
\hline Joy of life (range $0-100$ ) & $57.8(10.2)$ & - & & \\
\hline
\end{tabular}


Voerman, B., Fischer, M., Visser, A., Garssen, B., Andel, G. van, Bensing, J. Health-related quality of life in Dutch men with prostate cancer. Journal of Psychosocial Oncology: 2006, 24(2), 49-64

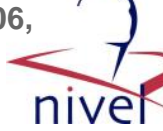

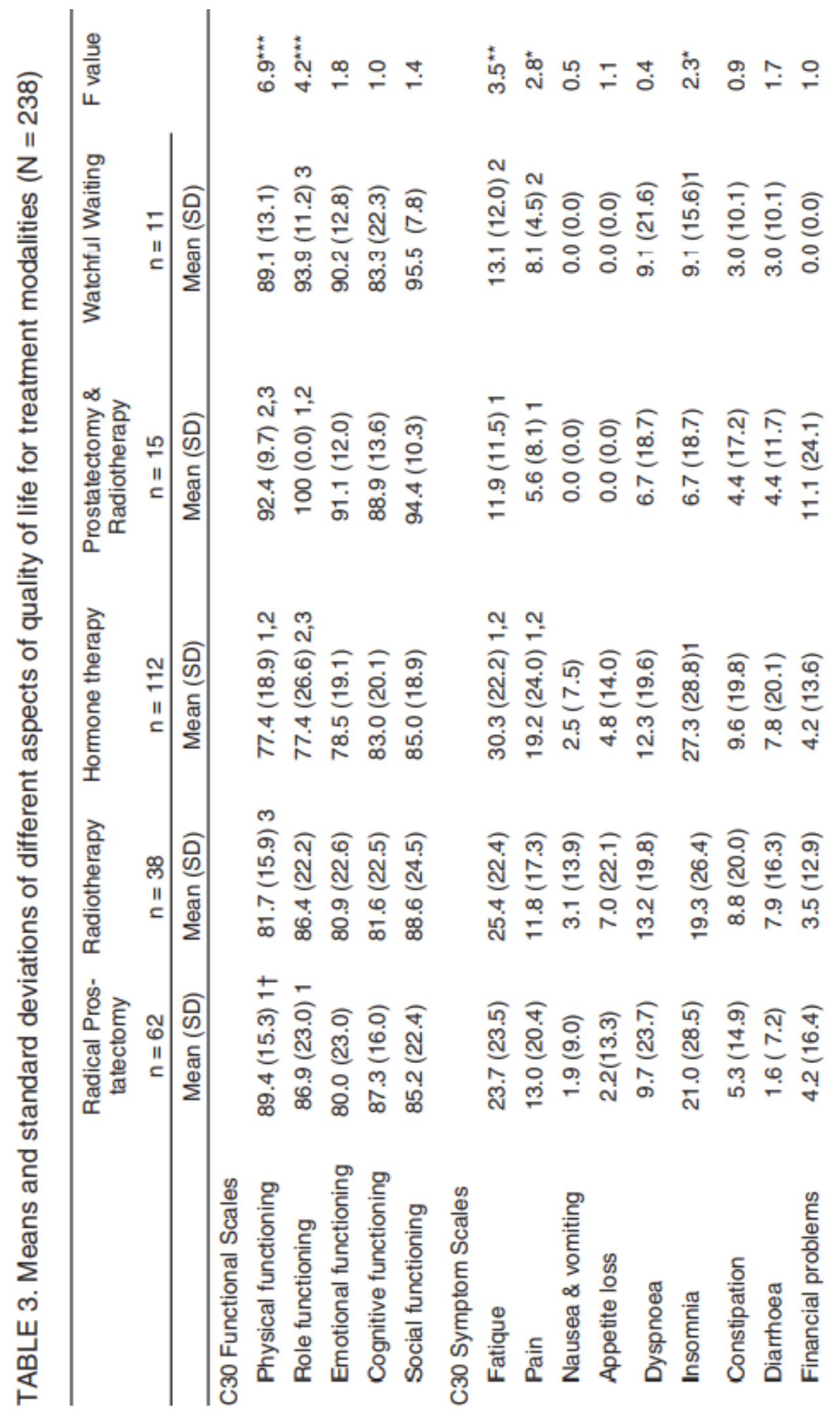


Voerman, B., Fischer, M., Visser, A., Garssen, B., Andel, G. van, Bensing, J. Health-related quality of life in Dutch men with prostate cancer. Journal of Psychosocial Oncology: 2006, 24(2), 49-64

\begin{tabular}{|c|c|c|}
\hline 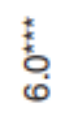 & 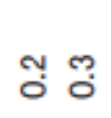 & 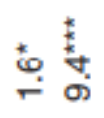 \\
\hline 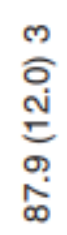 & 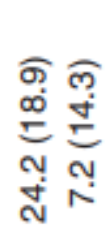 & 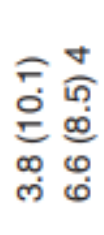 \\
\hline 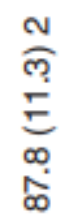 & 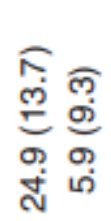 & 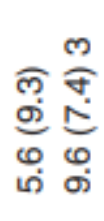 \\
\hline
\end{tabular}

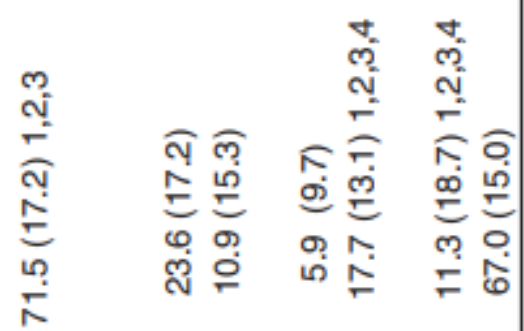

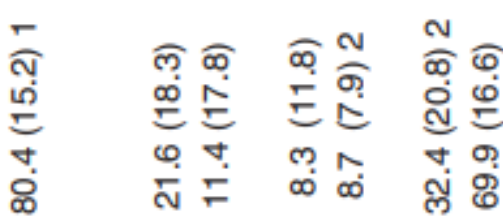

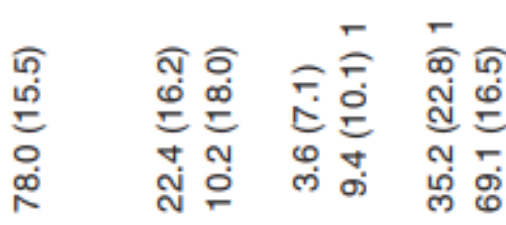

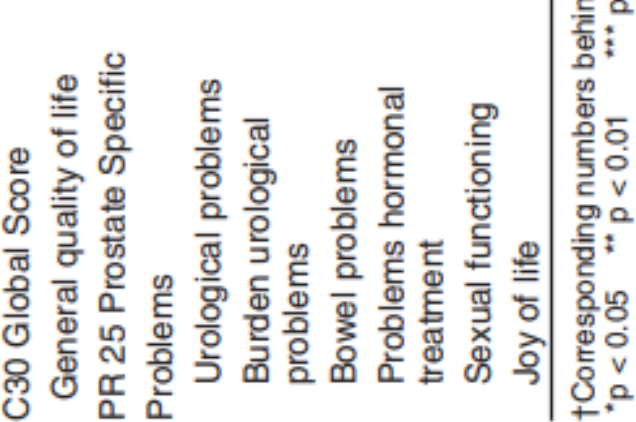

